\title{
ANALISIS POTENSI KAWASAN PESISIR PANTAI KOTA PADANG SEBAGAI WISATA OLAHRAGA MARATON BERSKALA INTERNASIONAL
}

\author{
Heru Pramudia \\ Program Studi Manajemen Perhotelan \\ Jurusan pariwisara \\ Fakultas Pariwisata dan Perhotelan \\ Universitas Negeri padang \\ E-mail: pramudia.heru@gmail.com
}

\begin{abstract}
Abstrak_ Kawasan wisata pantai Kota Padang tengah berbenah melalui pengenalan dan pengembangan sports tourism berkelas nasional dan internasional seperti marathon. Marathon merupakan salah satu olah raga yang populer, seperti New York City Marathon, Parias Marathon, Asia Tokyo Marathon, Tour De France, lomba perahu layar Bali. Penelitian ini bertujuan untuk pemetaan potensi pariwisata olahraga marathon berskala internasional, menganalisis potensi pariwisata olahraga dan kendala-kendala dalam pengembangan pariwisata. Peneliti mengobservasi lokasi pesisir pantai yang diperoleh dari narasumber/informan yang telah diuji coba dan digunakan untuk wisata olahraga marathon. Potensi internal wisata olahraga maraton ini "berpotensi tinggi" untuk diselenggarakan dengan kualitas atraksi wisata maraton dan kondisi lokasi tracking yang sangat baik. Potensi eksternal diantaranya aksesibilitas; fasilitas penunjang objek; fasilitas pelengkap, dan dukungan pengembangan objek, ini "berpotensi tinggi" untuk diselenggarakannya kegiatan Wisata Maraton berskala Internasional. Wisata maraton dapat diadakan dengan berbagai macam kriteria lomba dengan ikut serta melibatkan peran masyarakat sekitar; memberikan paket tawaran kegiatan yang menarik segala umur, informasi sarana pendukung yang jelas; memperkenalkan secara luas kepada masyarakat rangkaian kegiatan wisata maraton. Pemerintah membantu pengelolaan kegiatan usaha masyarakat; menghindari terjadinya pungli sehingga memberikan kenyamanan bagi wisatawan; area parkir yang disiapkan untuk mengantisipasi munculnya parkir liar; edukasi dan sangsi bagi masyarakat yang tidak menjaga kebersihan dan sangsi jika terjadi pungli.
\end{abstract}

Kata kunci : Potensi, Pariwisata, Olahraga, Maraton

\section{PENDAHULUAN}

Wisata olahraga menjadi salah satu peluang yang dapat mengingkatkan kegiatan kepariwisataan dan memajukan perekonomian masyarakat lokal. Upaya menggenjot wisata di Kota Padang adalah perlunya digalakkan olah raga maraton. Lari marathon merupakan lari yang biasa kita kenal dengan lari jarak jauh dengan lintasan yang berjarak 3000m keatas, $5000 \mathrm{~m}$, dan $10000 \mathrm{~m}$. Cabang lari yang satu ini dapat dilakukan di dalam maupun di luar stadion.

Akhir-akhir ini kawasan wisata pantai Kota Padang tengah berbenah dan dipromosikan.. Salah satu upaya yang dapat memajukan pariwisata antara lain melalui pengenalan dan pengembangan sports tourism berkelas nasional dan internasional seperti marathon. Marathon merupakan salah satu olah raga yang populer, seperti New York City Marathon, Parias Marathon, Asia Tokyo Marathon, Tour De France, lomba perahu layar Bali.

Kegiatan wisata olah raga yang berskala internasional dan nasional tersebut di atas diselenggarakan dengan harapan besar dapat menjadi media promosi kepariwisataan dan meningkatkan pendapatan dibidang pariwisata. Kota Padang perlu mengadakan kegiatan 


\section{D27 JURNAI

serupa agar orang lebih mengenal lagi ragam budaya dan daya tarik wisata yang dimiliki oleh kota tersebut.

Adapun tujuan penelitian ini untuk: (1) Mengidentifikasi potensi wisata dalam rangka penyelenggarakan kegiatan olah raga wisata maraton sehingga kegiatan ini layak untuk diselenggarakan di Kota Padang. Mengetahui strategi pengembangan sport tourism (wisata maraton) di Kota Padang. (3) Membuat rancangan skema kegiatan Wisata Maraton Kota Padang.

\section{METODE}

Metode yang digunakan dalam penelitian ini adalah metode analisa data sekunder yang diperoleh dari instansi terkait dan metode survei dengan penelitian yang menitikberatkan pada survei instansional yang didukung dengan observasi lapangan, penekanan analisanya menggunakan data sekunder, dengan menggunakan langkah-langkah sebagai berikut:

Penentuan Daerah Penelitian

Pemilihan daerah dilakukan secara purposive sampling artinya pemilihan daerah penelitian disesuaikan dengan maksud yang ingin dicapai dari penelitian yang dilakukan. Kawasan pesisir pantai Kota Padang dipilih sebagai daerah penelitian dengan pertimbangan sebagai daerah yang memiliki banyak potensi wisata olahraga maraton yaitu trek atau jalan sepanjang pantai yang sesuai dengan olah raga maraton.

Kawasan pesisir pantai Kota Padang ini memiliki daya tarik wisata dan terkelola dengan baik. Bentangan pesisir pantai mulai dari kawasan Pantai Muaro Lasak, lurus menuju Pantai Purus, jembatan Sitinurbaya, hingga terhubung oleh Bukit Gado-gado menuju kawasan Wisata Pantai Air Manis yang terkenal dengan legenda Batu Simalin Kundang. Berikut peta jalur Pesisir Pantai
Kota Padang yang biasa menjadi area maraton masyarakat kota Padang:

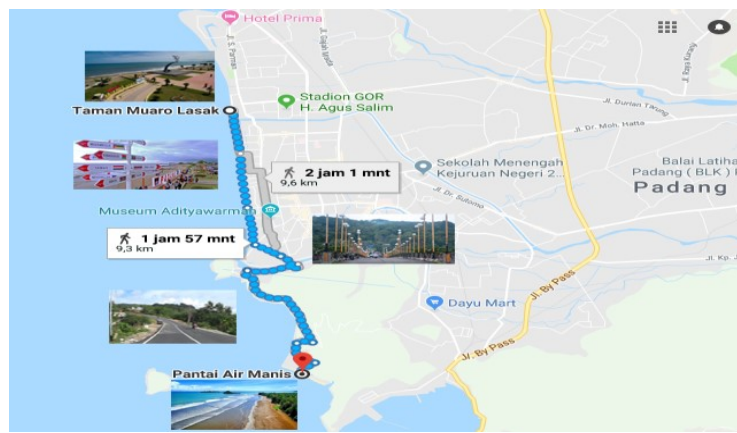

Gambar 2: Kawasan Pesisir Pantai Kota Kota Padan Sumber: Google Map dan Olahan Data Penelitian, 2018

\section{Teknik Pengumpulan Data}

Data yang dikumpulkan dalam penelitian ini adalah data primer dan data sekunder. Data primer diperoleh dari menginventaris sarana dan prasarana serta fasilitas yang tersedia pada sepanjang jaliur pesisir pantai Kota Padang dari Pantai Muaro Lasak sampai ke Pantai Air Manis.

Sedangkan data sekunder dikumpulkan dari Dinas Pariwisata dan pihak-pihak yang terkait, adapun jenis dan sumber data yang dikumpulkan adalah seperti pada tabel 1.6 berikut ini:

Table 1. Jenis dan Sumber Data Penelitian

\begin{tabular}{|c|l|l|}
\hline No & Jenis Data & Sumber Data \\
\hline 1 & $\begin{array}{l}\text { Lokasi daerah pesisir } \\
\text { pantai Kota Padang }\end{array}$ & $\begin{array}{l}\text { Kota Padang dalam } \\
\text { angka }\end{array}$ \\
\hline 2 & Peta Tematik & Google Map \\
\hline 3 & Pantai Muaro Lasak & Dinas Pariwisata \\
\hline 4 & Pantai Purus Padang & Dinas Pariwisata \\
\hline 5 & $\begin{array}{l}\text { Kawasan Jembatan } \\
\text { Siti Nurbaya }\end{array}$ & $\begin{array}{l}\text { Dunung Pariwisata } \\
\text { Padang/Bukit } \\
\text { Gado-gado }\end{array}$ \\
\hline 7 & Pantai Air Manis & Dinas Pariwisata \\
\hline
\end{tabular}

\section{Teknik Pengolahan dan Analisa Data}

Analisis data yang digunakan dalam penelitian ini adalah analisa data sekunder dengan teknik skoring dan klasifikasi. Klasifikasi digunakan untuk menentukan klasifikasi tingkat potensi 
obyek wisata dalam mendukung kegiatan wisata maraton yang dimulai dengan tahapan:

\section{a. Pemilihan Variabel Penelitian}

Langkah penting dalam suatu penelitian adalah menentukan variabel penelitian. Variabel adalah konsep yang mempunyai variasi nilai (Singarimbun, 1987). Dalam penelitian ini digunakan 2 variabel potensi yaitu (1) Potensi obyek wisata (Potensi Internal); (2) Potensi kawasan wisata (Potensi Eksternal). Menjelaskan tiap variabel yang dipilih dengan klasifikasi tinggi, sedang dan rendah, pengelompokkan data dari tiap variabel dilakukan dengan berbagai cara sesuai jenis-jenis bentuk data, model klasifikasi pada tahap ini dilakukan dengan tidak teratur, artinya disesuaikan dengan data yang ada.

\section{b. Skoring}

Adalah proses memberikan penilaian relatif atau skor 1 sampai 3. Adapun dibeberapa variabel sekor diberikan 1 sampai 2 (lihat pada tabel berikut):

\section{c. Klasifikasi Potensi Internal dan Eksternal}

Total skor pada variabel potensi obyek wisata dan total skor pada variabel potensi kawasan, kemudian diklasifikasikan yaitu klasifikasi tinggi, sedang dan rendah. Untuk mengetahui penilaian potensi gabungan dengan cara menggabungkan total skor dari semua variabel yang diteliti. Klasifikasi dilakukan dengan menggunakan interval kelas sebagai berikut :

Dimana : $\mathrm{K}=$ Klasifikasi

$\mathrm{a}=$ nilai skor tertinggi

$\mathrm{b}=$ nilai skor terendah

$\mathrm{u}=$ jumlah kelas

$$
K=\frac{u-a}{b}
$$

\section{d. Analisis SWOT}

Arah pengembangan obyek wisata dilakukan melalui analisi SWOT (Strenght, Weakness, Opportunitis, Threat). Proses pengambilan keputusan strategis selalu berkaitan dengan pengembangan misi, tujuan, strategi (strategic planer) harus menganalisis faktor-faktor setartegi perusahaan (kekuatan, kelemahan, peluang dan ancaman) dalam kondisi yang ada saat ini. Hal ini disebut analisis situasi. Model yang paling populer untuk analisis situasi adalah analisis SWOT (Rangkuit, 2001).

\section{HASIL DAN PEMBAHASAN}

Kawasan pesisir pantai Kota Padang ini memiliki daya tarik wisata dan terkelola dengan baik. Bentangan pesisir pantai mulai dari kawasan Pantai Muaro Lasak, lurus menuju Pantai Purus, Jembatan Siti Nurbaya, hingga terhubung oleh Bukit Gado-gado menuju kawasan Wisata Pantai Air Manis yang terkenal dengan legenda Batu Simalin Kundang. Berikut peta jalur Pesisir Pantai Kota Padang yang biasa menjadi area maraton masyarakat kota Padang:

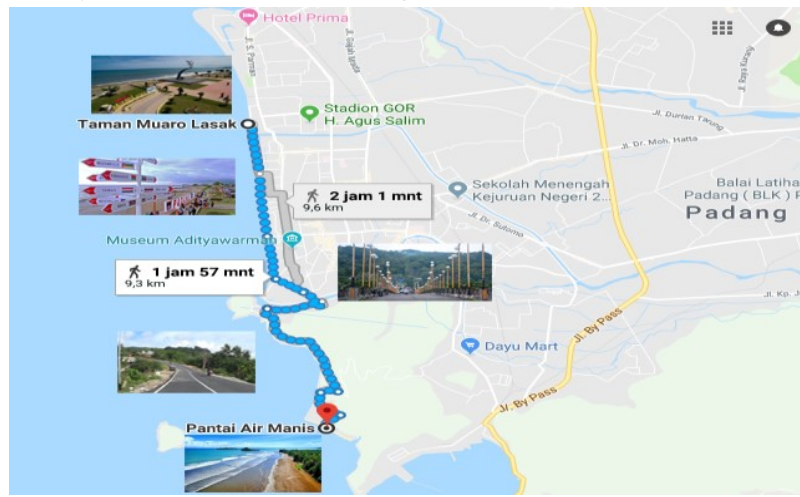

Gambar 4. Lokasi Treking Maraton 10KM Sepanjang Pesisir Pantai Kota Padang

Sumber: Google Map dan Olahan Data Penelitian, 2018

\section{A. Pantai Muaro Lasak}

Salah satu spot yang terkenal adalah Pantai Taman Muaro Lasak. Lokasi pantai ini masih dalam kawasan Pantai Purus, Kelurahan Rimbo Kaluang, Kecamatan Padang Barat, Kota Padang, Sumatera Barat. Pantai Muaro Lasak yang terletak berdampingan dengan pantai Padang ini memang memiliki banyak titik untuk mengabadikan gambar. Selain menikmati pemandangan pantai dengan 


\section{JPK NURNaI

bebatuan pemecah ombak yang tersusun rapi, masyarakat juga terlihat memenuhi Monumen Merpati Perdamaian yang baru diresmikan oleh Presiden Jokowi pada 12 April 2016. Masyarakat yang datang ke pantai Padang dan Pantai Muaro Lasak selalu menyempatkan diri untuk mengambil gambar di monumen dengan simbol burung merpati ini. Ombak yang terbilang landai membuat Anda aman dan nyaman untuk berenang. Anda dapat melihat pemandangan lepas yang sangat luas sejauh mata memandang. Ditambah kesejukan hembusan angin laut dengan ayunan ombak pantai. Suasana menjelang senja bertambah seru dengan adanya pemain paralayang yang hampir setiap hari melakukan aksinya. Tempat makan berjejeran di tepi pantai menggugah selera. Sederet makanan khas Minang dan cemilan tradisional menjadi favorit masyarakat.
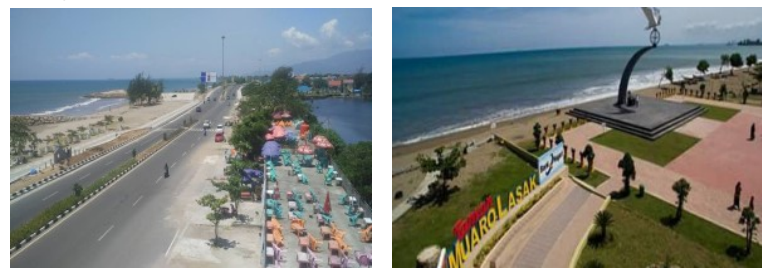

Gambar 5. Kondisi Jalan dan Pantai Muaro Lasak Sumber: Kaba Nagari, 2017

Area pantai ini dengan kondisi jalan yang cukup lebar dan luas, sehingga posisi garis Start sangat cocok di area ini. Terdapat dua lajur jalan raya yang sudah terpisah antara lajur kiri dan lajur kanan. Tetntunya peluang untuk digunakan sebahagian lajur sebagai area start maraton.

\section{B. Pantai Purus}

Pantai ini berada dipusat kota Padang sehingga akses menuju lokasi sangat mudah. Sebagai salah satu objek wisata Padang unggulan, pemerintah terus melakukan peningkatakan kualitas pantai sehingga terlihat sangat cantik dengan banyaknya bunga disekitar.
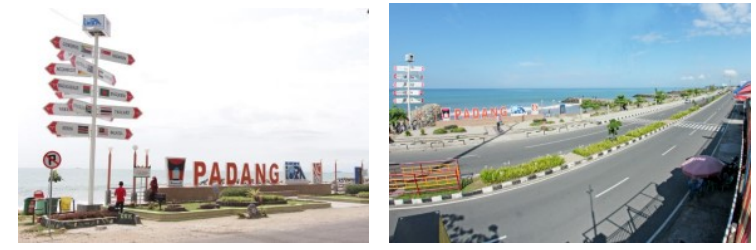

Gambar 6. Pantai Purus dan Kondisi Jalan Sumber: KSM Tour, 2018

Salah satu wisata murah meriah di tengah kota Padang adalah Pantai Purus atau nama lainnya Danau Cimpago. Pantai Purus berada di bagian barat Kota Padang, Sumatera Barat yang juga sejajar dengan objek wisata lain seperti Pantai Taman Muaro Lasak yang bersebelahan dengan Pantai Purus.

Pantai Purus memiliki pesisir yang cukup landai, pantainya sungguh cantik, area pasirnya cukup luas dengan lebar (sekitar 30-50 m dari jalan raya sampai ke laut) dengan tekstur halus dan lembut, sehingga cocok untuk arena bermain pasir bagi anak-anak. Pasir Pantai Purus tidak berwarna putih bersih, pasir pantai ini berwarna kecoklatan. Ombak pantai ini cukup besar (sekitar $2 \mathrm{~m}$ ) dan bergulung-gulung dengan bunyi yang keras. Ombak pantai ini sering dijadikan sebagai wahana berselancar bagi pehobi selancar.

Pantai ini selalu ramai di kunjungi terutama di sore hari, pengunjung pada umumnya memanfaatkan air pasang di sore hari untuk surfing atau bermain speed boat. Tiap akhir pekan dan hari libur banyak warga sekitar Kota Padang yang sengaja datang bersama keluarga. Kala sore menjelang, panorama sunset di pantai ini sangat bagus dan juga sering diincar-incar fotografer untuk diabadikan dalam sebuah foto.

Seperti halnya Pantai Taman Muaro Lasak, Pantai Purus juga mempunyai dermaga pemecah ombak. Pemandangan dari dermaga ini tak kalah menarik, Anda dapat melepas penglihatannya ke sepanjang pantai, Sungai/Batang Muaro ataupun ke arah deretan bangunan di belakang pantai. Untuk urusan perut, Pantai Purus juga merupakan jagonya kuliner seafood di Kota Padang. Jajaran warung seafood dengan lauk-lauk segar baru 
ditangkap terdapat di sekitar pantai ini. Di Pantai Purus pun banyak terdapat tenda warna-warni dengan kursi santai yang disediakan oleh pedagang. Berbeda dengan warung-warung seafood yang menjajakan makanan berat, pedagang di tenda-tenda hanya menawarkan makanan ringan saja seperti minuman dan snack.

\section{Jembatan Siti Nurbaya}

Salah satu ikon wisata di Kota Padang Sumatera Barat adalah Jembatan Siti Nurbaya. Jembatan ini adalah jembatan besar yang berdiri di atas Sungai/Muara Batang Arau. Panjang badan jembatan 100 meter dengan panjang total mulai dari kaki jembatan di jalan Nipah sampai dengan jalan Batang Arau sepanjang 600 meter. Jembatan ini juga menghubungkan kota tua Padang dengan Taman Siti Nurbaya, tempat Siti Nurbaya dimakamkan.

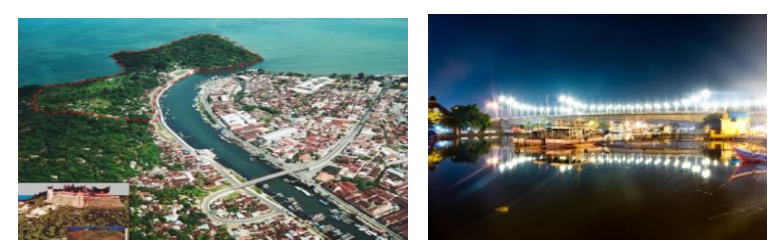

Gambar 7. Kawasan Jembatan Siti Nurbaya

Sumber: Aet, 2018

Asal usul nama jembatan siti nurbaya karena jembatan ini menghubungkan kawasan Kota Tua Padang di Berok Nipah dengan kaki Gunung Padang di seberangnya. Gunung Padang sendiri menurut novel Siti Nurbaya, merupakan bukit di tepi pantai dimana Siti Nurbaya pertama kali bertemu dengan kekasihnya Samsul Bahri, disitu juga mereka dimakamkan. Terlepas dari kebenaran cerita Siti Nurbaya, memang terdapat sebuah makam di puncak gunung Padang yang diklaim sebagai makam Siti Nurbaya.

Waktu yang paling cocok untuk mengunjungi lokasi wisata ini adalah pada waktu menjelang matahari terbenam, karena Anda dapat menyaksikan keindahan pemandangan matahari terbenam dari jembatan tersebut. Setelah itu area di sekitar jembatan akan dipenuhi oleh para penjual makanan yang menawarkan kuliner khas Padang sumatera barat dengan harga yang cukup bersahabat, disini Anda dapat mencicipi sate Padang, pisang bakar, jagung bakar dan berbagai minuman khas sesuai selera. Selain jembatan Siti Nurbaya, pesona kota Padang yang lainnya adalah bangunan-bangunan tua zaman Belanda di sekitar jembatan. Mulai dari jalan Pondok, Niaga, Kelenteng hingga jalan Batang Arau di dekat jembatan merupakan kawasan kota tua Padang. Kaum pendatang seperti Tionghoa, Nias, Mentawai dan Batak banyak bermukim disini. Sedangkan kaki gunung Padang merupakan kawasan makam Cina (bong). Di sebelah kanan dari kaki jembatan Siti Nurbaya terdapat gedung Bank Indonesia Padang lama yang telah selesai dipugar setelah kejadian gempa Padang tahun 2009. Lurus ke arah pusat kota di sepanjang jalan Nipah merupakan sentar oleh-oleh khas Padang seperti keripik balado dan rendang. Salah satu yang cukup terkenal adalah keripik balado Christine Hakim. Jika orang Padang akan pergi keluar daerah nama keripik balado Christine Hakim akan menjadi referensi utama.

\section{Bukit Gado-gado}

Bukit Gado-Gado sebuah lokasi tempat wisata yang baru dibuka oleh pemerintah kota Padang. Letaknya yang serangkai dengan Gunung Padang menyebabkan pengunjung mudah untuk menemukannya. Seiring dengan usaha pemerintah Sumatera Barat untuk mengembangkan pariwisata Sumatera Barat, pemerintah kota Padang juga giat membangun dan mengembangkan lokasi wisata di daerahnya. Salah satunya adalah pemda membangun jalan dari Muara Padang menuju Pantai Air Manis melewati Bukit Gado gado.

Dengan dibangunnya jalan dipunggung bukit gado gado ini, keindahan panorama dari 
bukit ini yang sebelumnya tidak bisa dinikmati banyak orang, sekarang dengan adanya jalan aspal hotmix selebar 6 meter, menyebabkan pengunjung membanjirinya setiap sore agar bisa menikmati indahnya sunset dari Bukit Gado gado.

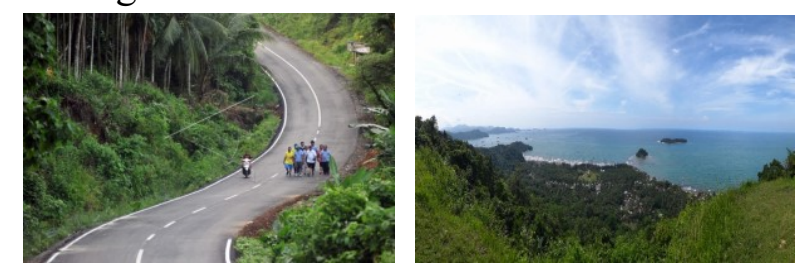

Gambar 8. Kawasan Treking Bukit Gado-gado Sumber: Antara, 2017

Disepanjang jalan dari Muara Padang ke Air Manis tempat Batu Malin Kundang yang telah melegenda ini, keindahan alamnya sangat menawan. Hutan yang masih asri dengan kicauan burung yang bersahutan menambah indahnya liburan anda. Menuju ke tempat ini tidak terlalu sulit. Setelah melintasi jembatan Siti Nurbaya yang menjadi ikon kota Padang, anda sampai di kaki gunung padang. Dari sini anda terus menuju puncak bukit melalui jalan hotmix yang tidak terlalu tajam pendakiannya. Hanya beberapa menit di atas mobil, anda sudah tiba di punggung bukit. Dari sini dengan leluasa anda bisa menikmati indahnya Samudra Hindia. Banyak warga saat ini yang memanfaatkan jalan di sepanjang bukit ini untuk olah raga joging di pagi ahad. Sedangkan sore hari mereka tumpah ruah ke punggung bukit untuk menikmati sunset. Banyak tempat mulai dibangun pedagang supaya pengunjung bisa duduk menikmati indahnya alam ciptaan Allah. Jangan khawatir dengan makanan dan minuman. Sebagaimana tempat wisata lain di Sumatera Barat, di sini banyak pedagang makanan yang menawarkan berbagai jenis kuliner

\section{E. Kawasan Wisata Pantai Air Manis}

Pantai ini terletak kurang lebih $10 \mathrm{~km}$ ke selatan dari pusat kota. Letaknya berada di belakang Gunung Padang atau tepatnya di Kecamatan Padang Selatan, Kota Padang.
Pantai ini merupakan salah satu tujuan wisata populer yang selalu ramai dikunjungi oleh masyarakat, terutama pada musim liburan sekolah atau lebaran. Air Manis atau dalam dialek Minang disebut 'aia manih' merupakan sebuah pantai dengan garis pantai yang lebar, kontur yang landai, dan berpasir cokelat keputihan.

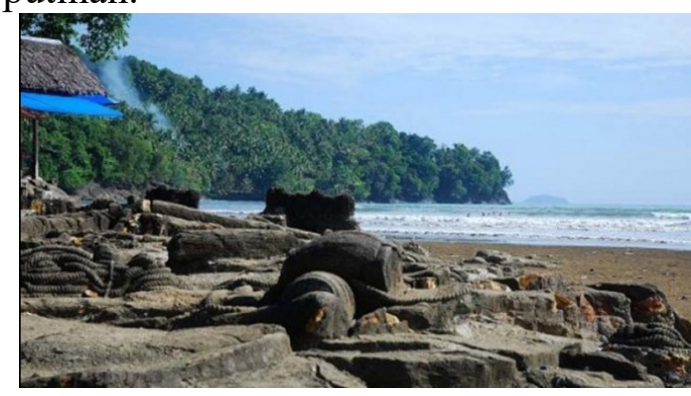

Gambar 9: Kawasan Pantai Airmanis

Sumber: Antara, 2017

Pantai ini dikenal dengan ombaknya yang kecil serta memiliki panorama yang indah di sisi utaranya. Di ujung utara pantai ini kita bisa melihat gundukan Gunung Padang dari kejauhan. Di samping itu, terdapat dua pulau kecil yaitu Pulau Pisang Kecil (pisang ketek) dan Pisang Besar (pisang gadang) yang berjarak tak seberapa jauh dari pantai ini. Selain panorama alam dan ombaknya, pantai ini tidak bisa dilepaskan dari Legenda Malin Kundang. Tak diragukan, legenda si Malin Kundang merupakan salah satu cerita rakyat paling populer dari Sumatera Barat. Bahkan popularitasnya menyebar ke berbagai penjuru Indonesia hingga pernah berkali-kali diangkat ke layar kaca dalam berbagai versi. Cerita penuh hikmah ini pun kerap kali dikisahkan sebagai perumpamaan mengenai pentingnya berbakti kepada orangtua. Legenda ini mengisahkan tentang bagaimana kemurkaan orangtua dapat berujung malapetaka bagi anaknya yang durhaka. Si Malin Kundang yang digambarkan sebagai seorang perantau sukses dikisahkan kembali ke kampungnya setelah bertahun-tahun merantau. Ia kembali dengan membawa istri dan kapalnya yang besar beserta pelayan-pelayannya. Dikisahkan, 
sesampainya di kampung halaman Malin enggan mengakui ibu kandungnya yang miskin bahkan mencacimaki dan mengusirnya. Karena sakit hatinya, sang ibu kemudian melontarkan sebuah kutukan agar si Malin berubah menjadi batu. Di sisi selatan pantai ini kita dapat melihat sebongkah batu yang menyerupai orang sedang sujud. Batu ini dipercaya sebagai Malin Kundang dikutuk dan yang telah berubah menjadi batu. Di sekelilingnya kita juga dapat menemukan batu-batu yang menyerupai reruntuhan dinding kapal yang dipercaya masyarakat sebagai bagian dari kapal Malin yang karam. Ada pula gulungan tali tambang serta gentong kayu yang terlihat sangat detail seakan-akan memang seperti tali tambang dan gentong kayu yang bertransformasi menjadi batu. Terlepas dari kebenaran legenda ini, keberadaan batu Malin Kundang menjadi daya tarik utama dari pantai ini. Meskipun dari penampilannya pantai ini masih memerlukan penataan, tetapi hal tersebut tidak menghalangi arus pengunjung yang penasaran dan ingin melihat langsung Batu Malin Kundang tersebut

\section{Identifikasi Potensi Area Treking Pesisir Pantai Kota Padang Identifikasi Potensi Internal}

Tabel 5: Hasil Variabel Penelitian dan Skor Potensi Wisata Olahraga Maraton (Identifikasi Potensi Internal)

\begin{tabular}{|c|c|c|c|c|}
\hline No & Indikator & Variabel & Kriteria & Skor \\
\hline \multirow[t]{4}{*}{1} & \multirow[t]{4}{*}{$\begin{array}{l}\text { Kualitas } \\
\text { Atraksi Wisata } \\
\text { Maraton }\end{array}$} & $\begin{array}{l}\text { a. Atraksi/daya tarik } \\
\text { utama objek wisata } \\
\text { maraton }\end{array}$ & $\begin{array}{l}\text { - Atraksi penangkap wisatawan } \\
\text { - Atraksi penahan wisatawan }\end{array}$ & $\frac{1}{2}$ \\
\hline & & $\begin{array}{l}\text { b. Kekuatan Komponen } \\
\text { atraksi wisata } \\
\text { maraton }\end{array}$ & $\begin{array}{l}\text { - Kombinasi komponen olahraga dan wisata yang dimiliki } \\
\text { kurang mampu mempertinggi kualitas kesan wisata } \\
\text { - Kombinasi komponen olahraga dan wisata yang dimiliki } \\
\text { mampu mempertinggi kualitas dan kesan wisata. }\end{array}$ & 1 \\
\hline & & $\begin{array}{l}\text { c. Kegiatan wisata } \\
\text { maraton di lokasi } \\
\text { wisata }\end{array}$ & $\begin{array}{l}\text { - Hanya kegiatan yang bersifat pasif (menikmati yang sudah } \\
\text { ada) } \\
\text { - Meliputi kegiatan yang bersifat pasif (menikmati yang sudah } \\
\text { ada) dan kegiatan yang bersifat aktif (berinteraksi dengan } \\
\text { objek) }\end{array}$ & 1 \\
\hline & & $\begin{array}{l}\text { d. Keragaman Kegiatan } \\
\text { Wisata Maraton }\end{array}$ & $\begin{array}{l}\text { - Wisata Maraton belum mampu menawarkan keberagaman } \\
\text { kegiatan pendukung } \\
\text { - Wisata Maraton menawarkan 1-2 kegiatan pendukung } \\
\text { lainnya } \\
\text { - Wisata Maraton menawarkan lebih dari } 2 \text { kegiatan } \\
\text { pendukung lainnya }\end{array}$ & 1 \\
\hline \multirow[t]{2}{*}{2} & \multirow{2}{*}{$\begin{array}{l}\text { Kondisi } \\
\text { Objek/Track } \\
\text { Wisata } \\
\text { Maraton }\end{array}$} & $\begin{array}{l}\text { e. Kondisi fisik objek } \\
\text { wisata maraton } \\
\text { secara langsung }\end{array}$ & $\begin{array}{l}\text { - Objek yang mengalami kerusakan dominan } \\
\text { - Objek yang sedikit mengalami kerusakan } \\
\text { - Objek belum mengalami kerusakan }\end{array}$ & $\begin{array}{l}1 \\
2\end{array}$ \\
\hline & & $\begin{array}{l}\text { f. kebersihan } \\
\text { lingkungan objek } \\
\text { wisata maraton } \\
\end{array}$ & $\begin{array}{l}\text { - Objek wisata kurang bersih dan tidak terawat } \\
\text { - Objek wisata cukup bersih dan terawat }\end{array}$ & 1 \\
\hline & & & TOTAL SKORING & 14 \\
\hline
\end{tabular}


Pengklasifikasian berdasarkan skor variabel potensi internal yaitu nilai skor maksimum (14) yang diperoleh dari jumlah angka masimal yang ada pada tiap skor variabel, dikurangi nilai skor minimum (6) yang diperoleh dari jumlah angka minimum dari tiap skor variabel sehingga diperoleh interval dibagi menjadi 3 (tiga) klasifikasi dengan formula sebagai berikut;

$$
K=\frac{14-6}{3}=2
$$

- Kelas potensi rendah bila nilai total skor obyek wisata $<6-9$
- Kelas potensi sedang bila nilai total skor obyek wisata 9-11

- Kelas potensi tinggi bila nilai total skor obyek wisata $>12-14$

Berdasarkan hasil penghitungan skor identifikasi potensi internal wisata olah raga maraton, didapatkan total skroing adalah 14 yaitu kelas potensi tinggi bila nilai total skor obyek wisata $>12-14$ yang artinya potensi internal wisata olahraga maraton ini "berpotensi tinggi" untuk diselenggarakan dengan kualitas atraksi wisata maraton dan kondisi lokasi tracking yang sangat baik

\subsubsection{Identifikasi Potensi Eksternal}

Tabel 6. Hasil Variabel Penelitian dan Skor Potensi Kawasan Wisata

(Identifikasi Potensi Eksternal)

\begin{tabular}{|c|c|c|c|c|}
\hline \multirow[t]{3}{*}{1} & \multirow[t]{3}{*}{ Aksesibilitas } & $\begin{array}{l}\text { g. waktu tempuh dari } \\
\text { terminal terdekat }\end{array}$ & $\begin{array}{l}\text { - Jauh (besar dari } 60 \text { menit) } \\
\text { - } \text { Agak jauh (30 s.d } 60 \text { menit) } \\
\text { - } \text { Tidak terlalu jauh (kecil dari } 30 \text { menit) }\end{array}$ & $\begin{array}{l}1 \\
2 \\
3\end{array}$ \\
\hline & & $\begin{array}{l}\text { h. Ketersediaan } \\
\text { angkutan umum } \\
\text { untuk menuju } \\
\text { lokasi objek } \\
\text { wisata. }\end{array}$ & $\begin{array}{l}\text { - Tidak tersedia angkutan umum menuju lokasi } \\
\text { objek } \\
\text { - Tersedia angkutan umum menuju lokasi } \\
\text { objek, tidak reguler } \\
\text { - Tersedia angkutan umum menuju lokasi } \\
\text { objek, bersifat reguler }\end{array}$ & 1 \\
\hline & & $\begin{array}{l}\text { i. Prasarana jalan } \\
\text { menuju objek } \\
\text { wisata }\end{array}$ & $\begin{array}{l}\text { - } \text { Tidak tersedia ke lokasi } \\
\text { - } \text { Tersedia, kondisi kurang baik } \\
\text { - Tersedia, kondisi beraspal baik }\end{array}$ & $\begin{array}{l}1 \\
2 \\
\end{array}$ \\
\hline \multirow[t]{2}{*}{2} & \multirow[t]{2}{*}{$\begin{array}{l}\text { Fasilitas Penunjang } \\
\text { Objek }\end{array}$} & $\begin{array}{l}\text { j. Ketersediaan } \\
\text { fasilitas } \\
\text { pemenuhan } \\
\text { kebutuhan } \\
\text { fisk/dasar dilokasi } \\
\text { objek wisata } \\
\text { 1. Rumah Makan } \\
\text { 2. Penginapan } \\
\text { 3. Bangunan } \\
\quad \text { untuk } \\
\text { menikmati } \\
\text { objek }\end{array}$ & $\begin{array}{l}\text { - } \text { Tidak tersedia } \\
\text { - } \text { Tersedia 1-2 jenis fasilitas } \\
\text { - } \text { Tersedia lebih dari } 2 \text { jenis fasilitas }\end{array}$ & $\begin{array}{l}1 \\
2 \\
3\end{array}$ \\
\hline & & $\begin{array}{l}\text { k. Ketersediaan } \\
\text { fasilitas } \\
\text { pemenuhan } \\
\text { kebutuhan sosial } \\
\text { wisatawan dilokasi } \\
\text { objek: } \\
\text { 1. Taman } \\
\text { terbuka } \\
\text { 2. Fasilitas seni }\end{array}$ & $\begin{array}{l}\text { - } \text { Tidak tersedia } \\
\text { - Tersedia } 1-2 \text { jenis fasilitas } \\
\text { - Tersedia lebih dari } 2 \text { jenis fasilitas }\end{array}$ & $\begin{array}{l}1 \\
2 \\
3 \\
\end{array}$ \\
\hline
\end{tabular}




\begin{tabular}{|c|c|c|c|c|}
\hline & & $\begin{array}{l}\text { dan budaya } \\
\text { 3. Tempat } \\
\text { ibadah }\end{array}$ & & \\
\hline 3 & Fasilitas pelengkap & $\begin{array}{l}\text { 1. Ketersediaan } \\
\text { fasilitas pelengkap } \\
\text { yang terdiri dari: } \\
\text { 1. Tempat } \\
\text { parkir } \\
\text { 2. Toilet } \\
\text { 3. Pusat } \\
\text { informasi } \\
\text { 4. Souvenir } \\
\text { Shop }\end{array}$ & $\begin{array}{l}\text { - } \text { Tidak tersedia } \\
\text { - } \text { Tersedia 1-2 jenis fasilitas } \\
\text { - } \text { Tersedia lebih dari } 2 \text { jenis fasilitas }\end{array}$ & $\begin{array}{l}1 \\
2 \\
3 \\
\end{array}$ \\
\hline \multirow[t]{3}{*}{4} & \multirow[t]{3}{*}{$\begin{array}{l}\text { Dukungan } \\
\text { Pengembangan } \\
\text { Objek }\end{array}$} & $\begin{array}{l}\text { m. Keterkaitan } \\
\text { antar objek }\end{array}$ & $\begin{array}{l}\text { - Objek tunggal berdisi sendiri } \\
\text { - Objek paralel, terdapat dukungan objek } \\
\text { wisata lain }\end{array}$ & $\frac{1}{2}$ \\
\hline & & $\begin{array}{l}\text { n. Dukungan paket } \\
\text { wisata }\end{array}$ & $\begin{array}{l}\text { - bila objek wisata tidak termasuk dalam } \\
\text { agenda keunjungan dari suatu paket wisata } \\
\text { - bila objek wisata termasuk dalam agenda } \\
\text { kunjungan dari suatu paket wisata }\end{array}$ & 1 \\
\hline & & $\begin{array}{l}\text { o. Pengembangan } \\
\text { dan promosi objek } \\
\text { wisata }\end{array}$ & $\begin{array}{l}\text { - Objek wisata belum dikembangkan dan } \\
\text { belum terpublikasi } \\
\text { - Objek wisata sudah dikembangkan serat } \\
\text { sudah terpublikasikan }\end{array}$ & 1 \\
\hline & & & TOTAL SKORI & 24 \\
\hline
\end{tabular}

Pengklasifikasin berdasarkan skor variabel potensi eksternal yaitu nilai skor maksimum (24) yang diperoleh dari jumlah angka masimal yang ada pada tiap skor variabel, dikurangi nilai skor minimum (9) yang diperoleh dari jumlah angka minimum dari tiap skor variabel sehingga diperoleh interval dibagi menjadi 3 (tiga), klasifikasi dengan formula sebagai berikut;

$$
K=\frac{24-9}{3}=5
$$

- Kelas potensi rendah bila nilai total skor obyek wisata $<19-14$

- Kelas potensi sedang bila nilai total skor obyek wisata $15-18$

- Kelas potensi tinggi bila nilai total skor obyek wisata $>19-24$

Berdasarkan hasil penghitungan skor identifikasi potensi eksternal wisata olahraga maraton, didapatkan total skroing adalah 24 yaitu Kelas potensi tinggi bila nilai total skor obyek wisata $>19-24$ yang artinya potensi eksternal diantaranya aksesibilitas;

\section{fasilitas penunjang objek; fasilitas} pelengkap, dan dukungan pengembangan objek, ini "berpotensi tinggi" untuk diselenggarakan.

\section{Analisis SWOT Potensi Wisata Olahraga Maraton di Pesisir Pantai Kota Padang.}

Potensi wisata olahraga maraton di kawasan pesisir pantai Kota Padang dengan analisis swot dapat dilihat pada tabel berikut ini:

Sumber data Informan sebagai berikut:

A1 : Kaprodi Jurusan Olahraga Kesehatan dan Olahraga Rekreasi UNP

A2 : Dosen Jurusan Olahraga Kesehatan dan Rekreasi (UNP)

A3 : Dosen Jurusan Olahraga Kesehatan dan Rekreasi (UNP)

B1 : Kepala Dinas Pariwisata dan Kebudayaan Kota Padang

B2 : Kabag Promosi Dinas Pariwisata dan Kebudayaan Kota Padang

C1 : Kepala Dinas Pemuda dan Olahraga Kota Padang 


\section{JPK \\ Volume 11 No. 1 Juni 2019 \\ e-ISSN: 2549-9823 p-ISSN: 2085-4285

\section{Matrik SWOT Potensi Wisata Olahraga Maraton di Pesisir Pantai Kota Padang}

\section{Tabel 7. Matrik SWOT POtensi Wisata Olahraga}

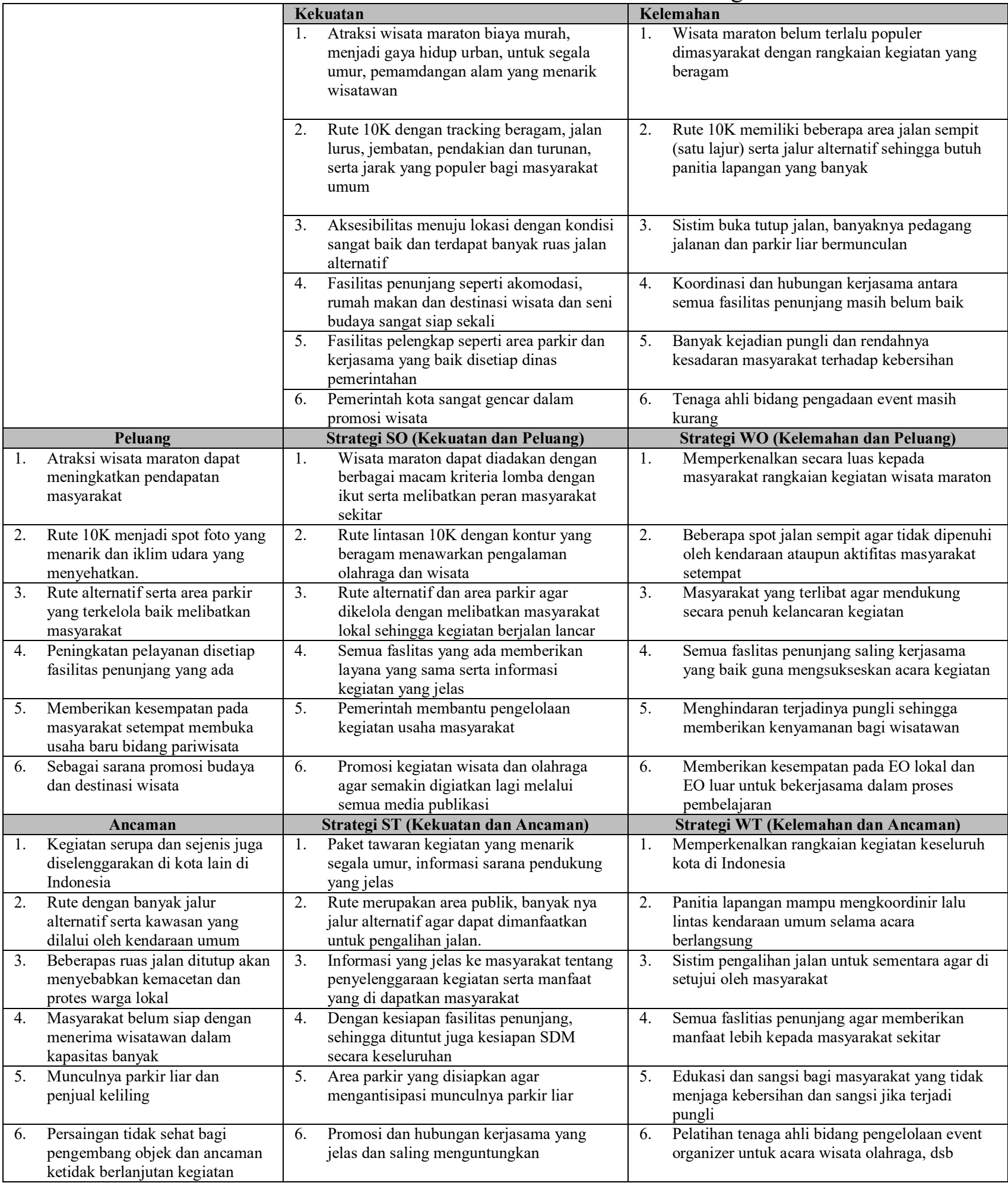




\section{KESIMPULAN}

1) Potensi internal wisata olahraga maraton ini "berpotensi tinggi" untuk diselenggarakan dengan kualitas atraksi wisata maraton dan kondisi lokasi tracking yang sangat baik

2) Potensi eksternal diantaranya aksesibilitas; fasilitas penunjang objek; fasilitas pelengkap, dan dukungan pengembangan objek, ini "berpotensi tinggi" untuk diselenggarakannya kegiatan Wisata Maraton berskala Internasional.

3) Wisata maraton dapat diadakan dengan berbagai macam kriteria lomba dengan ikut serta melibatkan peran masyarakat sekitar; memberikan paket tawaran kegiatan yang menarik segala umur, informasi sarana pendukung yang jelas; memperkenalkan secara luas kepada masyarakat rangkaian kegiatan wisata maraton; memperkenalkan rangkaian kegiatan keseluruh kota di Indonesia.

4) Lintasan $10 \mathrm{~K}$ dengan kontur yang beragam menawarkan pengalaman olahraga dan wisata; beberapa spot jalan sempit agar tidak dipenuhi oleh kendaraan ataupun aktifitas masyarakat setempat; rute lintasan merupakan area publik, banyaknya jalur alternatif agar dapat dimanfaatkan untuk pengalihan jalan; panitia lapangan mampu mengkoordinir lalu lintas kendaraan umum selama acara berlangsung.

5) Masyarakat yang terlibat agar mendukung secara penuh kelancaran kegiatan; jalan alternatif dan area parkir agar dikelola dengan melibatkan masyarakat lokal sehingga kegiatan berjalan lancar; informasi yang jelas ke masyarakat tentang penyelenggaraan kegiatan serta manfaat yang didapatkan masyarakat; sistim pengalihan jalan untuk sementara agar di setujui oleh masyarakat.

6) Semua faslitas yang ada memberikan layanan yang sama, serta informasi kegiatan yang jelas; semua faslitas penunjang saling kerjasama yang baik guna mengsukseskan acara kegiatan; dengan kesiapan fasilitas penunjang sehingga dituntut juga kesiapan SDM secara keseluruhan; semua faslitias penunjang agar memberikan manfaat lebih kepada masyarakat sekitar.

7) Pemerintah membantu pengelolaan kegiatan usaha masyarakat; menghindari terjadinya pungli sehingga memberikan kenyamanan bagi wisatawan; area parkir yang disiapkan untuk mengantisipasi munculnya parkir liar; edukasi dan sangsi bagi masyarakat yang tidak menjaga kebersihan dan sangsi jika terjadi pungli.

8) Promosi kegiatan wisata dan olahraga agar semakin digiatkan lagi melalui semua media publikasi; memberikan kesempatan pada EO lokal dan EO profesional untuk bekerjasama dalam proses pembelajaran; promosi dan hubungan kerjasama yang jelas dan saling menguntungkan; pelatihan tenaga ahli bidang pengelolaan event organizer untuk acara wisata olahraga, dsb.

\section{DAFTAR PUSTAKA}

Antara. 2017. Pesona Bukit Gado-gado dan Jalan Lingkar Teluk Bayur. https://www.antarafoto.com/bisnis/v1 514881201/jalan-lingkar-teluk.

Aet. 2018. Jembatan Siti Nurbaya di Kota Padang Nan Melegenda. https://aet.co.id/pariwisata/jembatan-s iti-nurbaya-di-kota-padang-nan-mele genda Bola Sport. 2017. Lomba Maraton Paling Keren di Indonesia. https://www.bolasport.com/ragam/18 
2990-6-lomba-maraton-paling-kerenyang-ada-di-indonesia-nomor-5-diada kan-diIndonesia. Diunduh Kamis 25/01/2018 Pukul 07:38 wib

CNN Indonesia. 2017. Pikat Wisman, Pariaman Gelar Ajang Triathlon. https://www.cnnindonesia.com/gayahidup/20171129185601-307-259038/ pikat-wisman-pariaman-gelar-ajang-t riathlon. Diunduh Kamis 25/01/2018 Pukul 07:38 wib

Cooper, John Fketcher, David Gilbert and Stephen Wanhill. (1995). Tourism, Principles and Practice. London: Logman.

Jateng Tribunew. 2017. Borobudur Maraton Kembali Digelar. (http://jateng.tribunnews.com/2017/0 9/16/borobudur-maraton-kembali-dig elar-buruan-daftar-peserta-dibatasi. Diunduh Kamis 25/01/2018 Pukul 07:38 wib

Kaba Nagari. 2017. Pemko Padang Larang Bus Pariwisata. https://www.kabarnagari.com/2017/0 4/pemko-padang-larang-bus-pariwisa ta.html

KSM Tour. 2018. Pantai Purus SUmatera Barat Wisata Bagi Pecinta Surfing. https://ksmtour.com/informasi/tempat -wisata/sumatera-barat/pantai-purus-s umatera-barat-wisata-mengasyikkanbagi-pecinta-surfing.htmlTribunnews. 2107. Batam Barelang Bridge International Marathone 2017. http://jateng.tribunnews.com/2017/11 /25/bp-batam-barelang-bridge-interna tional-marathon-2017-ajang-lari-palin g-sensasional?page $=3$. Diunduh Kamis 25/01/2018 Pukul 07:38 wib

Minang News. 2017. Liburan Lebaran Pantai Padang Paling Favorit Dikunjungi.

https://minangkabaunews.com/artikel -9397-libur-lebaran-pantai-padang-p aling-favorit-dikunjungi.html.

Diunduh Kamis 25/01/2018 Pukul 07:38 wib. 